\title{
Bone morphogenetic protein 7 sensitizes 06-methylguanine methyltransferase expressing-glioblastoma stem cells to clinically relevant dose of temozolomide
}

Jonathan L. Tso', Shuai Yang ${ }^{1,2}$, Jimmy C. Menjivar ${ }^{1}$, Kazunari Yamada ${ }^{1,3}$, Yibei Zhang ${ }^{1,4}$, Irene Hong ${ }^{1}$, Yvonne Bui ${ }^{1}$, Alexandra Stream', William H. McBride ${ }^{5,10}$, Linda M. Liau, ${ }^{6,10}$, Stanley F. Nelson ${ }^{7,10}$, Timothy F. Cloughesy ${ }^{8,10}$, William H. Yong 9,10, Albert Lai ${ }^{8,10}$ and Cho-Lea Tso ${ }^{1,10^{*}}$

\begin{abstract}
Background: Temozolomide (TMZ) is an oral DNA-alkylating agent used for treating patients with glioblastoma. However, therapeutic benefits of TMZ can be compromised by the expression of O6-methylguanine methyltransferase (MGMT) in tumor tissue. Here we used MGMT-expressing glioblastoma stem cells (GSC) lines as a model for investigating the molecular mechanism underlying TMZ resistance, while aiming to explore a new treatment strategy designed to possibly overcome resistance to the clinically relevant dose of TMZ (35 $\mu \mathrm{M})$.

Methods: MGMT-expressing GSC cultures are resistant to TMZ, and IC50 (half maximal inhibitory concentration) is

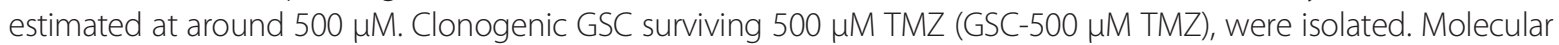
signatures were identified via comparative analysis of expression microarray against parental GSC (GSC-parental). The recombinant protein of top downregulated signature was used as a single agent or in combination with TMZ, for evaluating therapeutic effects of treatment of GSC.

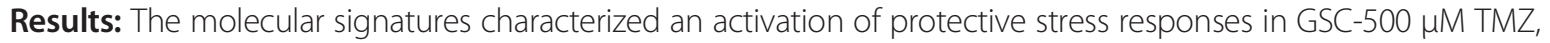
mainly including biotransformation/detoxification of xenobiotics, blocked endoplasmic reticulum stress-mediated apoptosis, epithelial-to-mesenchymal transition (EMT), and inhibited growth/differentiation. Bone morphogenetic protein 7 (BMP7) was identified as the top down-regulated gene in GSC-500 $\mu$ M TMZ. Although augmenting BMP7 signaling in GSC by exogenous BMP7 treatment did not effectively stop GSC growth, it markedly sensitized both GSC-500 $\mu \mathrm{M}$ TMZ and GSC-parental to $35 \mu \mathrm{M}$ TMZ treatment, leading to loss of self-renewal and migration capacity. BMP7 treatment induced senescence of GSC cultures and suppressed mRNA expression of CD133, MGMT, and ATP-binding cassette drug efflux transporters (ABCB1, ABCG2), as well as reconfigured transcriptional profiles in GSC by downregulating genes associated with EMT/migration/invasion, stemness, inflammation/immune response, and cell proliferation/tumorigenesis. BMP7 treatment significantly prolonged survival time of animals intracranially inoculated with GSC when compared to those untreated or treated with TMZ alone $(p=0.0017)$, whereas combination of two agents further extended animal survival compared to BMP7 alone $(p=0.0489)$.

(Continued on next page)
\end{abstract}

\footnotetext{
* Correspondence: ctso@mednet.ucla.edu

'Department of Surgery/Surgical Oncology, David Geffen School of Medicine,

University of California at Los Angeles, Los Angeles, CA, USA

${ }^{10}$ Jonsson Comprehensive Cancer Center, University of California at Los

Angeles, Los Angeles, USA

Full list of author information is available at the end of the article
} 
(Continued from previous page)

Conclusions: These data support the view that reduced endogenous BMP7 expression/signaling in GSC may contribute to maintained stemness, EMT, and chemoresistant phenotype, suggesting that BMP7 treatment may provide a novel strategy in combination with TMZ for an effective treatment of glioblastoma exhibiting unmethylated MGMT.

Keywords: BMP7, Glioblastoma, Temozolomide, MGMT, Glioblastoma stem cells

\section{Background}

Glioblastoma is the most common and lethal primary malignant brain tumor which remains a challenging disease to treat. The current standard-of-care for patients with newly diagnosed glioblastoma consists of maximal surgical resection, radiotherapy (RT), and concomitant and adjuvant chemotherapy with temozolomide (TMZ). Despite aggressive treatment, all patients eventually suffer from tumor progression because their tumors become resistant to maintenance TMZ, and the median survival among all patients is only $12-15$ months from diagnosis. Although TMZ is the principal first-line chemotherapeutic agent used for the treatment of glioblastoma, it does not significantly prolong the overall survival of patients without methylation of the MGMT promoter [1-3]. The antitumor activity of TMZ depends on its ability to methylate DNA at the O-6 positions of guanine residues, which will produce methylguanine adducts, triggering a continuous cycle of DNA base mismatch repair, which leads to double-strand breaks and base mispairing, ultimately inducing cell apoptosis $[4,5]$. MGMT is a cellular DNA repair protein that neutralizes the cytotoxic effects of TMZ by directly transferring methyl groups from the O-6-position of guanine to a cysteine residue [6]. Therefore, glioblastoma tumors expressing MGMT have been implicated as a major intrinsic mechanism of resistance to TMZ, although a different mechanism independent of MGMT has been reported [7]. Methylation of MGMT promoter has become an important prognostic and predictive factor for TMZ treatment of newly diagnosed GBM, and high MGMT protein expression in patient tumors is associated with TMZ resistance in patients $[8,9]$. Thus, treatment strategies to overcome MGMT-dependent or independent chemoresistance are urgently needed.

It has been hypothesized that glioblastoma stem cells (GSC) are responsible for post-treatment tumor recurrence because they are drug-resistant cells that can survive treatment and regenerate tumors [10-13]. A recent study using a genetically engineered mouse model of glioma has provided direct evidence and demonstrated that a quiescent subset of endogenous stem-like glioma cells is located at the apex of a cellular hierarchy in tumor maintenance, and is responsible for tumor recurrence after TMZ therapy fails [14]. This study thus supports the view that TMZ can only deplete the proliferative differentiated tumor population, but not the quiescent
GSC. It is generally accepted that GSC are a small subset of slow-cycling stem-like glioblastoma tumor cells within a tumor tissue, that are capable of clonally self-renewing and growing as tumor spheres and migrating radially outward in culture, and reconstituting a tumor in mouse brain that recapitulates the histopathological features of the patient tumor from which the GSC were derived [15-17]. A previous study indicated that MGMT-negative CSC line can be depleted with $50 \mu \mathrm{M}$ TMZ treatment in culture whereas GSC line expressing MGMT transcripts results in a 10-fold increase of TMZ-resistance $(500 \mu \mathrm{M})$ [18]. Similarly, we also found that GSC clones resistant to radiochemotherapy expressed upregulated MGMT when compared to that of autologous sensitive GSC clones [13]. Current adjuvant TMZ treatment is given as 150$200 \mathrm{mg} / \mathrm{m}^{2}$ on days 1 to 5 of a 28-day cycle, which results in concentrations of between $15-35 \mu \mathrm{M}$ in glioma tumor tissue [19]. Therefore, identifying a new strategy to sensitize the MGMT-expressing GSC to clinically achievable dose of TMZ in brain will have important implications for the management of glioblastoma patients with unmethylated MGMT promoter.

In this study, we extended our previous work and used MGMT-expressing GSC that survived $500 \mu \mathrm{M}$ TMZ treatment (GSC-500 $\mu \mathrm{M} \mathrm{TMZ}$ ) to explore the potential intrinsic factors that may be linked to triggering TMZ resistance. By comparing gene-expression profiles between GSC-500 $\mu \mathrm{M}$ TMZ and parental GSC (GSC-parental), we explored a series of genes that characterized intracellular stress responses and self-defense mechanisms against high-dose TMZ in GSC-500 $\mu \mathrm{M}$ TMZ. Moreover, BMP7 was identified as a top down-regulated gene in GSC-500 $\mu \mathrm{M}$ TMZ. We thus evaluated the treatment efficacy of recombinant BMP7 on GSC and tested the synergistic effect of BMP7 and low-dose TMZ on the treatment of MGMT-expressing GSC both in vitro and in vivo. We further investigated the potential MGMT-independent mechanisms contributing to the BMP7-mediated sensitization of MGMT-expressing GSC to TMZ.

\section{Results}

GSC cultures contain tumorigenic clones that are resistant to high-dose TMZ and express upregulated MGMT

Three previously established and characterized patient tumor-derived MGMT unmethylated GSC cell lines, 
D431, S496 and E445 [13, 17, 20] were used to study TMZ sensitivity. A cell viability assay was performed to determine the dose-dependent effect and IC50 of TMZ for GSCs (Fig. 1a). Cells were plated at clonal density and treated with various doses of TMZ $(0,200,500,800$, $1000 \mu \mathrm{M})$ and incubated for $48 \mathrm{~h}$ prior to measurement of their growth activity. All three GSC lines are relatively resistant to $200 \mu \mathrm{M}$ TMZ, but showed a dose response to higher-dose TMZ treatment (Fig. 1a); the IC50 value of TMZ against three tested GSC lines is found to be approximately $500 \mu \mathrm{M}$. To understand how high-dose TMZ affects the growth activity of GSC, we compared their cell-cycle distributions in their normal untreated state, and after both 48-hour and 7-day exposure to TMZ. The cell cycle analysis at 48-hr time point of $500 \mu \mathrm{M}$ TMZ treatment revealed a robust cell cycle arrest in the S phase for all 3 tested GSC (D431/23\%, S496/31 \%, E445/27 \% Vs. 52 \%, 62 \%, 53 \% respectively), whereas arrest in $\mathrm{G} 2 / \mathrm{M}$ phase was only observed in 2 cultures $(12 \%, 14 \%, 20 \%$ Vs. $40 \%, 13 \%, 32 \%$ respectively) (Fig. 1b, $a-f$ ). TMZ-induced cellular damage was clearly seen on day- 7 cultures and resulted in a sub-G1 peak where $26-42 \%$ of apoptotic cells were determined (Fig. 1b, g-i). Meanwhile, several clonogenic cells survived and started to re-populate tumor spheres, and large tumor spheres can be seen on day 10 for all three
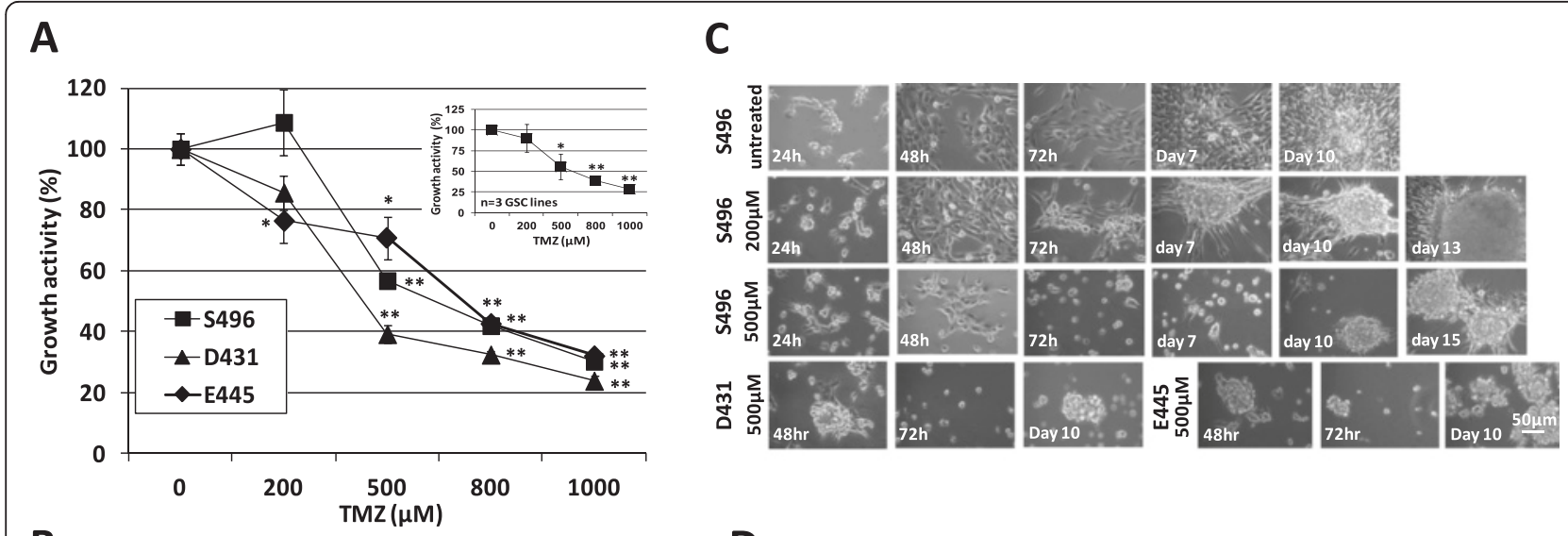

B
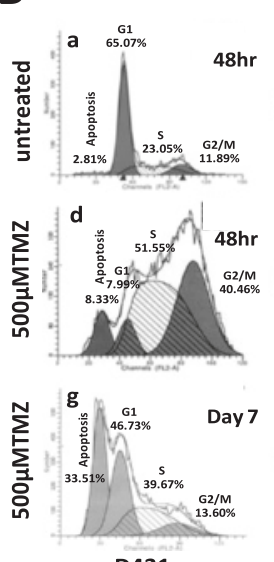

D431
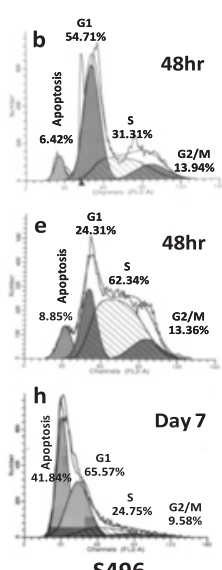

S496
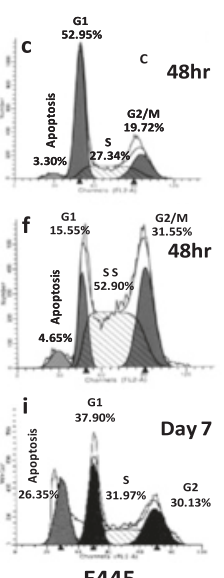

D
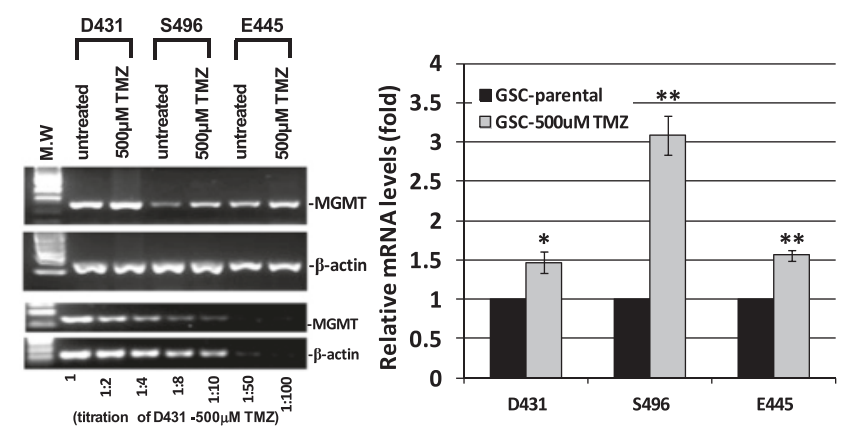

Fig. 1 A selection of clonogenic GSC clones able to survive high-dose TMZ treatment from MGMT-expressing GSC culture lines. a. Growth activity of GSC lines treated with indicated TMZ doses was determined via MTS-based cell proliferation assay. The dose response curve of GSCs derived from each patient tumor, is presented both individually and combined together. The concentration of TMZ required for $50 \%$ inhibition of GSC viability in vitro (IC50) was estimated using the mean of growth activity of 3 GSC lines. Values of TMZ-treated cells represent the percentage of growth relative to that of untreated cells, which was converted to $100 \%$. Data represent mean values \pm SD of triplicate measurements of three independent experiments. ${ }^{*} p<0.05$ and ${ }^{* *} p<0.001$ in relation to untreated control. b. Cell cycle distribution of GSC treated with and without $500 \mu \mathrm{M}$ TMZ was determined on day 2 or day 7 after treatment. Numbers in the respective cell cycle distributions indicate the percentage of cells in each phase of the cell cycle. $\mathbf{c}$. In vitro selection of clonogenic survival of GSC in the presence of 200 or $500 \mu \mathrm{M}$ TMZ or left untreated. Photos were taken at indicated time periods after treatment. d. sqRT-PCR analysis of MGMT mRNA expression levels in untreated parental GSC (GSC-parental) and clonogenic clones surviving 500 MM TMZ treatment (GSC-500 $\mu \mathrm{M}$ TMZ). The graph shows the mean values of fold change for MGMT mRNA expression levels in indicated GSC-500 $\mu$ M TMZ lines relative to those of untreated GSC-parental. All values are relative to those of the internal control gene $\beta$-actin, with values of GSC-500 $\mu M$ $T M Z$ representing the fold change relative to that of GSC-parental, which was converted to 1. Data represent mean values \pm SD of triplicate measurements in three independent experiments. ${ }^{*} p<0.05$ and ${ }^{* *} p<0.001$ in relation to GSC-parental 
cultures (Fig. 1c). When compared to untreated, parental GSC, these clonogenic GSC surviving $500 \mu \mathrm{M}$ TMZ, designated as GSC-500 $\mu \mathrm{M}$ TMZ, expressed upregulated DNA repair enzyme MGMT mRNA as determined by semi-quantitative RT-PCR (sqRT-PCR) (Fig. 1d). To test whether GSC-500 $\mu \mathrm{M}$ TMZ possess tumorigenic capacity, cells were stereotactically injected into the brains of severe combined immunodeficient (SCID) mice. Mice which received cells derived from GSC-parental ( 5 mice per GSC line) or GSC-500 $\mu \mathrm{M}$ TMZ (5 mice per GSC line) all developed tumors, while delayed tumor development was determined in all 3 GSC-500 $\mu \mathrm{M}$ TMZ lines (Fig. 2a, b).
The H-E staining of xenograft tumors initiated by GSCparental or GSC-500 $\mu \mathrm{M}$ TMZ showed no histological difference between the two groups, indicating that in vitro selection by high-dose TMZ did not alter/destroy the properties and histological origin of GSC. All tumors demonstrated invasive growth of gliomas with diffuse infiltration into the surrounding tissue and vessels, and recapitulated the typical histopathological features of human glioblastoma (Fig. 2c). These data indicated that MGMTexpressing GSC-parental cultures contain minor stem-like tumor-initiating cells with inherent properties that allow them to adapt to deadly stress induced by high-dose TMZ.

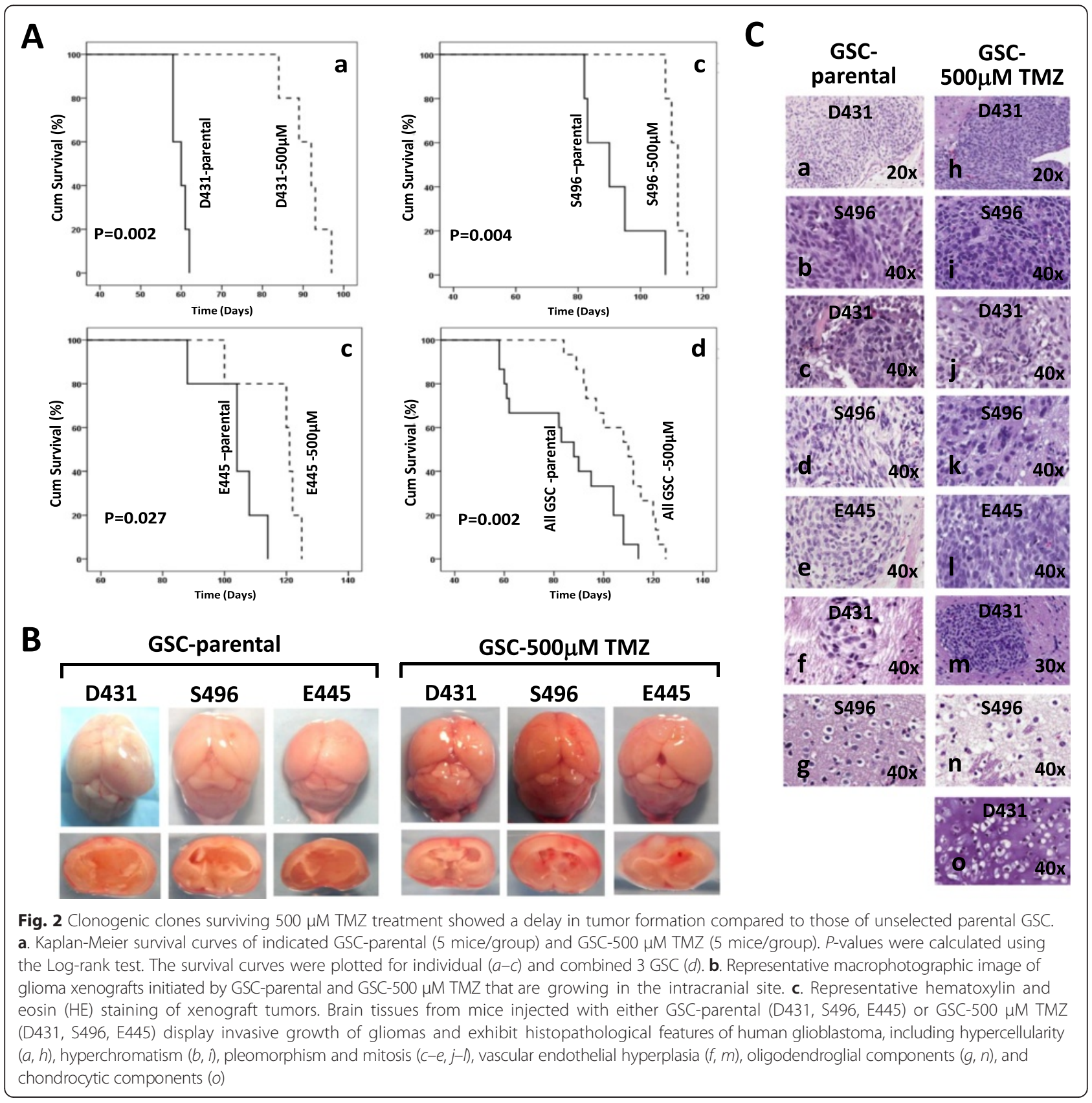




\section{Molecular profiles of GSC-500 $\mu \mathrm{M}$ TMZ revealed an intrinsic defense strategy against high- dose TMZ}

To explore the intrinsic mechanisms allowing clonogenic clones to overcome or adapt to $500 \mu \mathrm{M}$ TMZ, we performed a comparative high-density expression microarray analysis of GSC-parental ( $n=3$ patients, duplicate/ 6 samples) and GSC-500 $\mu \mathrm{M}$ TMZ survived one and two-cycle $500 \mu \mathrm{M}$ TMZ treatment $(n=3$ patients, 6 samples). Probe set signals on the expression array that were $\geq 1.5$-fold higher or lower in GSC-500 $\mu \mathrm{M}$ TMZ group versus the GSC-parental group with a pairwise ttest $(P<0.05)$ were selected, and 36 informative genes were obtained (Table 1). As anticipated, the overall gene expression profile revealed the activation of stress response pathways for self-defense and stabilizing cellular/ genomic integrity, including blocking of endoplasmic reticulum stress-mediated apoptosis (GRP), biotransformation of xenobiotics/detoxification (NNMT), inhibition of insulin/Akt signaling (EGR1, INPP4B), induction of cellular quiescence/growth inhibition (CDKN1A, NR2F1, SLFN5. PPP1R14C, ZNF652, PRRG4), stabilization of mitochondria/microtubule network (MAP4), promoting EMT, migration/invasion (RUNDC3B, MCAM, NR2F1, RRAS, FN1, MALAT1), angiogenesis (GRP, APOLD1, FN1, MALAT1), and suppression of cell proliferation and differentiation (downregulated BMP7, FJX1). The distinct gene expression in GSC-parental and GSC-500 $\mu \mathrm{M}$ TMZ was confirmed by sqRT-PCR analysis (Additional file 1 : Figure S1). To test whether upregulated "defense signatures" indeed provide protection from TMZ treatment, cells were treated with siRNA targeting selected defense signatures for $48 \mathrm{~h}$ prior to receiving $35 \mu \mathrm{M}$ TMZ. Active clonogenic growth was detected in cells treated with siRNA negative control with or without addition of $35 \mu \mathrm{M}$ TMZ even though less growth was seen in TMZ-treated wells, the on-target knockdown of selected defense signatures have resulted in a severe loss of ability to repopulate tumor spheres (Fig. 3a, $a$; Additional file 1: Figure S2). Moreover, adding $35 \mu \mathrm{M}$ TMZ after knockdown of defense genes further lysed tumor sphere-initiating cells (Fig. 3a, $a$; Additional file 1: Figure S2), which was not seen in those transfected with siRNA targeting housekeeping gene, glyceraldehyde-3-Phosphate Dehydrogenase (GAPDH) (Fig. 3a, a). On-target gene knockdown by siRNA treatment was verified by sqRT-PCR analysis (Fig. 3a, b) and gene knockdown at protein levels was validated in two representative genes, using Western blot analysis (NNMT) and enzyme assay (GAPDH) (Fig. 3b). The differential growth effect of siRNA treatment on GSC was further validated by cell proliferation assay and a TMZ-specific synergy was demonstrated in GSC knockdown of defense signature, not GAPDH $(p<0.001)$ (Fig. 3c). These results suggest that some of the upregulated genes in GSC-500 $\mu \mathrm{M}$ TMZ not only serve as essential factors for maintaining GSC integrity, but also play a key role in maintaining resistance against lethal stress induced by high-dose TMZ.

\section{BMP7 treatment reverses chemoresistance of MGMT-expressing GSC to TMZ}

BMP7 was identified as the top down-regulated gene in GSC-500 $\mu \mathrm{M}$ TMZ by expression microarray analysis when compared to autologous GSC-parental and suggested the endogenous BMP7 expression in GSC may play a role in regulating drug resistance to TMZ. We therefore, focused our study on BMP7 for the following reasons: recombinant BMP7 is readily available, it can cross the blood-brain barrier (BBB) [21], and it has been regarded as a metastatic suppressor gene. Since all tested GSC cultures expressed BMP type 2 receptors (BMPR2) (Fig. 4a, a), and BMP7 treatment induced phosphorylation of Smad1/5/8 protein (Fig. 4a, $b$ ), we hypothesized that augmenting BMP7 signaling in GSC would attenuate stemness and EMT properties, and sensitize cells to TMZ treatment via switching off defense genes. To test this hypothesis, both GSC-parental and GSC-500 $\mu \mathrm{M}$ TMZ were seeded and either treated with TMZ $(35 \mu \mathrm{M})$, BMP7 (100 ng/ml), combination of BMP7 and TMZ, or left untreated. In the combination treatment, GSC were pre-treated with BMP7 for overnight, and again on the following day by adding BMP7 to cultures for $30 \mathrm{~min}$ prior to TMZ treatment. All treatments were repeated for 5 consecutive days. GSC treated with $35 \mu \mathrm{M}$ TMZ only showed minimal growth effect when compared to untreated GSC. Although GSC treated with BMP7 showed less cell migration and proliferation when compared to untreated GSC, no cell death/lysis was observed in cultures, and cells continued to grow after treatment (Fig. 4b). In contrast, combination treatment with BMP7 and TMZ showed a progressive suppression of both cell proliferation and migration starting on day 5 after the first treatment, eventually leading to cell apoptosis/lysis (Fig. 4b, c, $a, b$ ). The treatment effects were further evaluated by a $\beta$-galactosidase senescence assay, and the data showed that senescence cells were detected only in cultures treated with BMP7 alone or combination with TMZ (Fig. 4c, c). These observations suggest that protective factors that cause chemoresistance which include antisenescence, were attenuated when BMP7 signaling was activated, rendering cells more vulnerable, and thereby more sensitive to low-dose TMZ.

\section{BMP7 modulates molecular properties of GSC associated} with treatment resistance

Previous studies have pointed out that the expression of MGMT/unmethylated MGMT [2, 3, 18], CD133 [22-24], and ATP-binding cassette drug efflux transporters [25-27] are important intrinsic factors contributing to 
Table 1 Molecular signatures and defense profiles of glioblastoma stem cells (GSC) resistant to 500 $\mu M \mathrm{TMZ}^{\mathrm{a}}$

\begin{tabular}{|c|c|c|c|}
\hline Gene & Fold change & $P$ value & Functional involvement \\
\hline MB2: metastasis related protein & 9.48 & 0.037251 & human lung cancer cell metastasis-related gene \\
\hline GRP: gastrin-releasing peptide & 3.03 & 0.012739 & $\begin{array}{l}\text { activates stress responses; blocks ER stress-mediated } \\
\text { apoptosis; angiogenesis }\end{array}$ \\
\hline NNMT: nicotinamide N-methyltransferase & 3.02 & 0.016864 & $\begin{array}{l}\text { biotransformation of xenobiotics, detoxification, } \\
\text { drug resistance, DNA repair }\end{array}$ \\
\hline RUNDC3B: RUN domain containing 3B & 2.63 & 0.022848 & tumor invasion, tumorigenic capacity, malignant transformation \\
\hline $\begin{array}{l}\text { PPP1R14C: protein phosphatase 1, regulatory (inhibitor) } \\
\text { subunit } 14 \mathrm{C}\end{array}$ & 2.45 & 0.038521 & $\begin{array}{l}\text { tumor suppressor, upregulates early growth response } 1 \text { and } \\
\text { PTEN gene expression }\end{array}$ \\
\hline FAM46A: family with sequence similarity 46 , member A & 2.35 & 0.026347 & retinal signaling pathways \\
\hline SYTL2: synaptotagmin-like 2 & 2.07 & 0.006201 & vesicle trafficking \\
\hline EGR1: early growth response 1 & 2.00 & 0.012287 & $\begin{array}{l}\text { impaired insulin/Akt signaling, reduced glucose uptake, } \\
\text { autophagy, Sirt1 expression }\end{array}$ \\
\hline ZNF652: zinc finger protein 652 & 1.88 & 0.024023 & a transcriptional repressor, tumor suppressor \\
\hline MAP4: microtubule-associated protein 4 & 1.85 & 0.007016 & $\begin{array}{l}\text { stabilizes mitochondria, microtubule network, and } \\
\text { cell viability }\end{array}$ \\
\hline APOLD1: apolipoprotein L domain containing 1 & 1.85 & 0.006038 & angiogenesis, blood-brain permeability \\
\hline ANKRD10: ankyrin repeat domain 10 & 1.85 & 0.011112 & unknown \\
\hline C5orf32: chromosome 5 open reading frame 32 & 1.79 & 0.005850 & stress tolerance \\
\hline SLFN5: Schlafen family member 5 & 1.74 & 0.025479 & growth-inhibitory responses, tumor suppressor \\
\hline MCAM: melanoma cell adhesion molecule & 1.73 & 0.004659 & cell adhesion, EMT \\
\hline MST150: MSTP150 & 1.72 & 0.010533 & induced by nerve growth factor \\
\hline NR2F1: Nuclear receptor subfamily 2, group F, member 1 & 1.68 & 0.003457 & tumor dormancy, cell motility, and invasiveness \\
\hline $\begin{array}{l}\text { PRRG4: Proline rich Gla (G-carboxyglutamic acid) } 4 \\
\text { (transmembrane) }\end{array}$ & 1.65 & 0.009662 & downregulates ERK 1/2 signaling, cell cycle control \\
\hline RRAS: related RAS viral (r-ras) oncogene homolog & 1.62 & 0.022906 & maintains endothelial barrier function, cell migration \\
\hline CDKN1A: cyclin-dependent kinase inhibitor 1A (p21, Cip1) & 1.60 & 0.018892 & cell cycle regulator, cellular quiescence, tumor suppressor \\
\hline FAM1 14A1: family with sequence similarity 114 , member A1 & 1.59 & 0.026679 & neuronal cell development \\
\hline INPP4B: inositol polyphosphate-4-phosphatase, type II, 105kDa & 1.57 & 0.004296 & $\begin{array}{l}\text { phospholipid metabolism, tumor suppressor, } \\
\text { inhibits PI3K/Akt signaling }\end{array}$ \\
\hline FN1: fibronectin 1 & 1.56 & 0.037537 & EMT, cell adhesion and migration, angiogenesis \\
\hline C6orf57: chromosome 6 open reading frame 57 & 1.54 & 0.036557 & mitochondrial function \\
\hline VDAC1: voltage-dependent anion channel 1 & 1.52 & 0.005105 & respiratory electron transport \\
\hline PSAT1: phosphoserine aminotransferase 1 & 1.52 & 0.029482 & $\begin{array}{l}\text { serine synthesis pathway; amino acid/phospholipid/nucleotide } \\
\text { synthesis }\end{array}$ \\
\hline ZEB1: zinc finger E-box binding homeobox 1 & 1.51 & 0.038506 & transcriptional repression of interleukin 2 \\
\hline $\begin{array}{l}\text { MALAT1: metastasis associated lung adenocarcinoma } \\
\text { transcript } 1\end{array}$ & 1.51 & 0.021777 & EMT, migration, invasion, metastasis, angiogenesis \\
\hline FAT3: FAT tumor suppressor homolog 3 (Drosophila) & 1.51 & 0.014515 & controls neuronal morphology \\
\hline MFSD2: major facilitator superfamily domain containing 2 & -1.53 & 0.006302 & plays a role during fasting and adaptive thermogenesis \\
\hline NUP160: nucleoporin 160kDa NUP98: nucleoporin 98kDa & -1.55 & 0.049580 & $\begin{array}{l}\text { promotes mitotic spindle assembly, contributes to proper } \\
\text { kinetochore functions }\end{array}$ \\
\hline NUP98: nucleoporin 98kDa & -1.59 & 0.032310 & a nuclear pore complex component; a transcription factor \\
\hline DPP6: dipeptidyl-peptidase 6 & -1.06 & 0.013619 & interaction with extracellular matrix \\
\hline FJX1: four jointed box 1 (Drosophila) & -1.62 & 0.004725 & growth and differentiation \\
\hline NRP2: neuropilin 2 & -1.63 & 0.041599 & cardiovascular development, axon guidance, and tumorigenesis \\
\hline BMP7: bone morphogenetic protein 7 (osteogenic protein 1) & -1.98 & 0.002699 & cartilage and bone formation; differentiation and proliferation \\
\hline
\end{tabular}

ER endoplasmic reticulum; EMT epithelial-to-mesenchymal transition

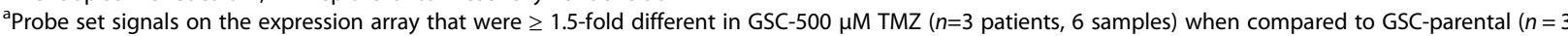
patients, duplicate samples) by a pairwise t-test $(P<0.05)$, were selected. Samples were permutated 100 times by dChip, and 36 annotated genes with median $\mathrm{FDR}=4 \%$ were obtained 


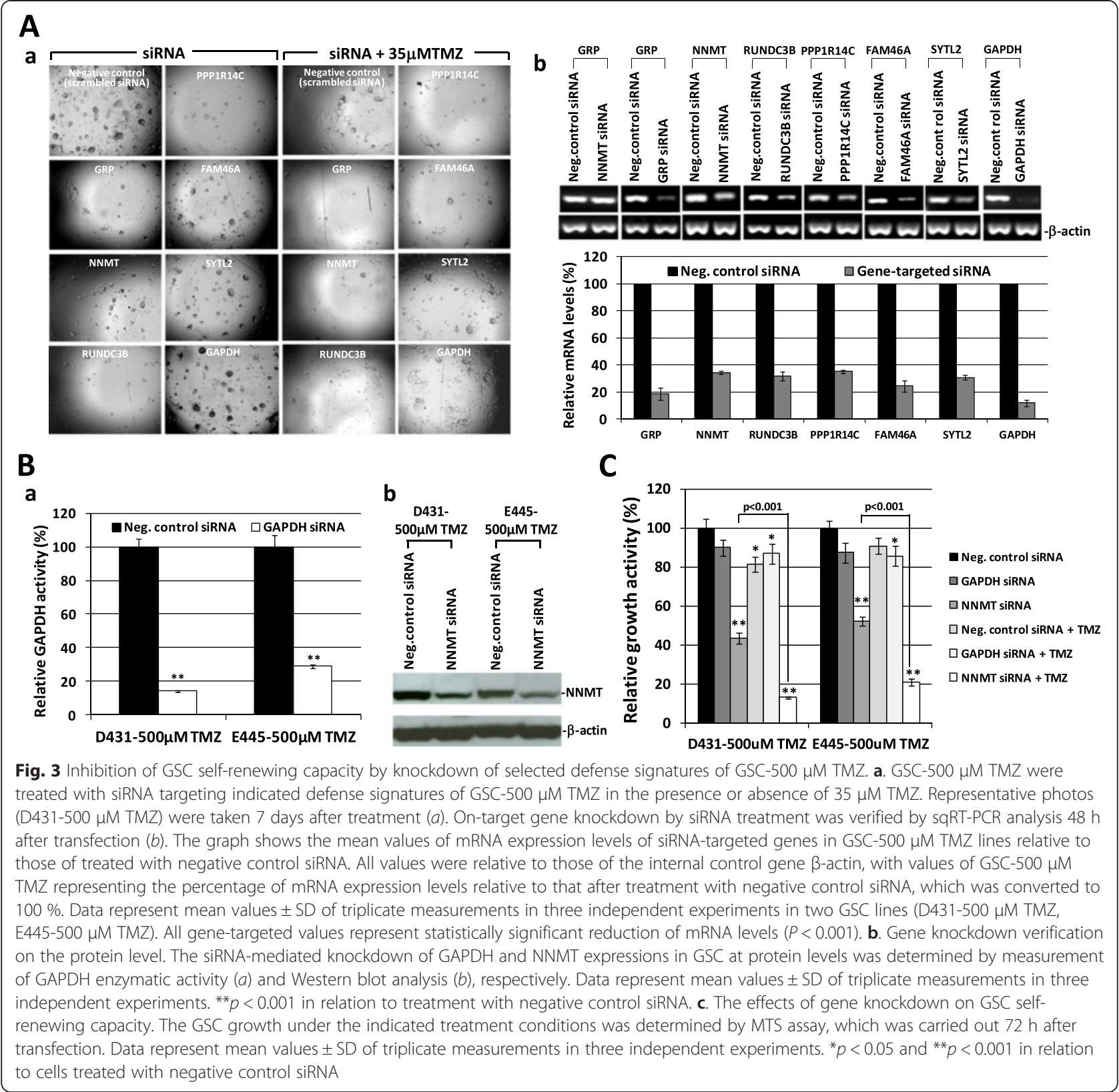

TMZ resistance. We therefore, tested whether we can establish this relationship using MGMT-expressing GSC model. Although BMP7 did not suppress GSC growth effectively in culture as compared to combination treatment (Fig. 4b, c), the BMP7 treatment has induced the loss of CD133 transcripts accompanied by down-regulated MGMT and two drug efflux transporters, ABCB1 (also known as P-glycoprotein or multidrug resistance protein 1) $[25,26]$ and ABCG2 (breast cancer resistance protein, BCRP) [26, 27] in GSC (Fig. 5a). The expression of SRY (sex determining region Y)-box 2 (SOX2), a marker for neural stem cells, was also decreased but in a lesser degree. Down-regulation of stem cell- associated markers in GSC was more likely to decrease their expression in formerly expressing cells in response to BMP7 treatment, rather than depleting them due to all mRNA samples being extracted $24 \mathrm{~h}$ after the first treatment was performed (day 3). Unexpectedly, the expression of glial fibrillary acidic protein (GFAP), a marker of differentiated astrocytes, was not upregulated, but is almost undetectable, while the expression of Nestin remained unchanged. GFAP expressing neural stem cells (NSC) have been reported, although CD133-expressing cells represent a more quiescent NSC-like population [28, 29]. A comparable transcriptional pattern was also seen in GSC treated with BMP7 + TMZ: the expressions of ABCB1 and 


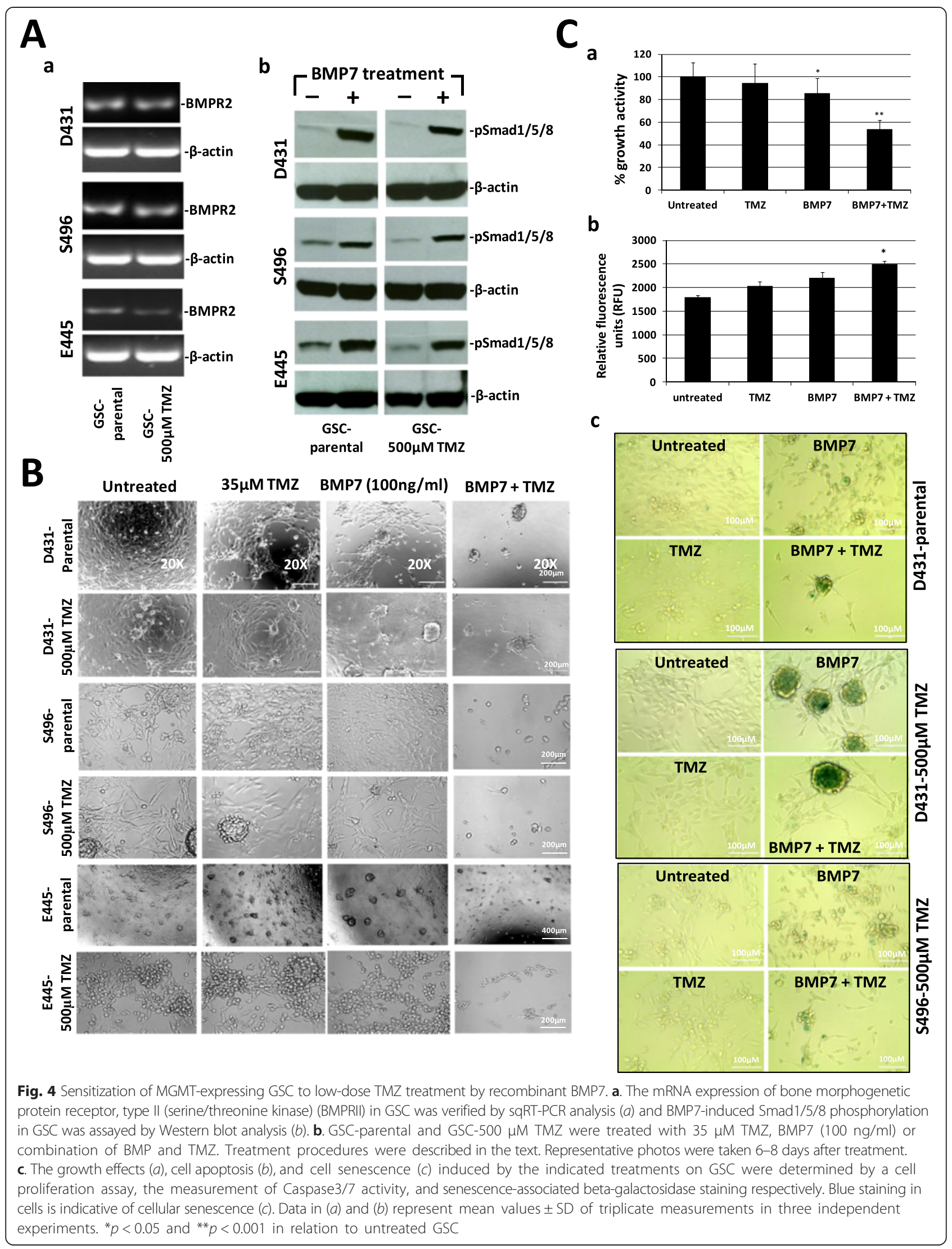




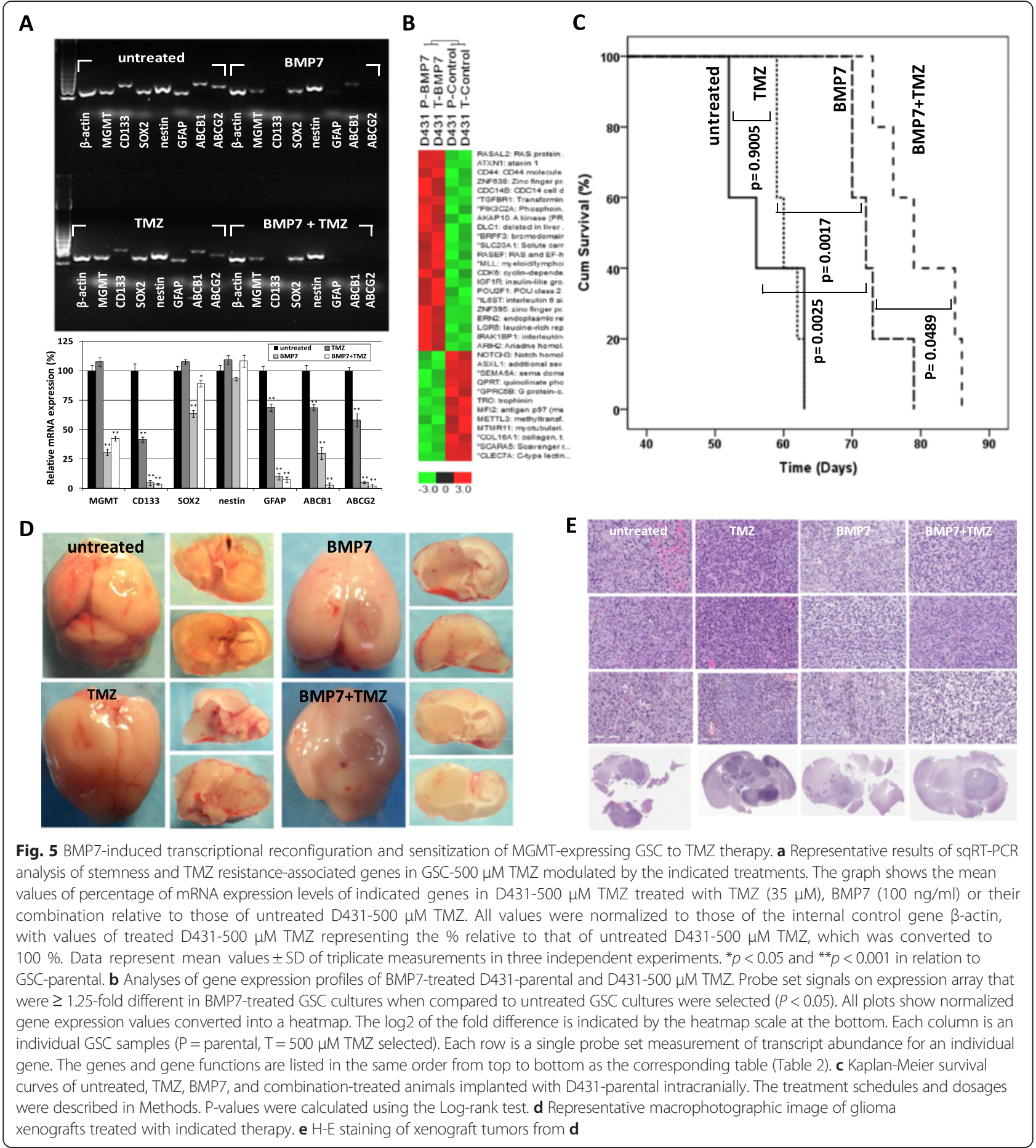

ABCG2 were almost not detectable. In contrast, the expression of these tested markers remained present in GSC treated with TMZ alone, but the expression levels were lower than those of untreated GSC (Fig. 5a). Moreover, down-regulation of MGMT mRNA levels by BMP7 treatment was not due to the reversal of MGMT promoter methylation status (Additional file 1: Figure S3), suggesting methylation-independent pathways of MGMT expression regulation. In order to obtain more comprehensive knowledge about gene regulation by BMP7 treatment in GSC, we performed an expression microarray analysis to identify genes that were differentially expressed between untreated and BMP7-treated GSC (Fig. 5b, Table 2) in both GSC-parental and GSC-500uM TMZ. DNA microarray demonstrated that BMP7 treatment upregulated a cluster of genes associated with metastasis 
Table 2 Transcriptional modulation in GSC by BMP7 treatment ${ }^{a}$

\begin{tabular}{|c|c|c|c|}
\hline Gene & Fold change & $P$ value & Functional involvement \\
\hline \multicolumn{4}{|l|}{ I. Upregulated genes } \\
\hline RASAL2: RAS protein activator like 2 & 3.37 & 0.019083 & tumor and metastasis suppressor \\
\hline ATXN1: ataxin 1 & 2.59 & 0.013118 & $\begin{array}{l}\text { chromatin-binding factor that repress Notch signaling, cell } \\
\text { differentiation }\end{array}$ \\
\hline CD44: CD44 molecule (Indian blood group) & 2.59 & 0.023871 & $\begin{array}{l}\text { a receptor for hyaluronic acid; modulates Smad1 activation } \\
\text { in the BMP7 signaling }\end{array}$ \\
\hline ZNF638: protein 638 & 2.33 & 0.030429 & adipocyte differentiation \\
\hline $\begin{array}{l}\text { CDC14B: CDC14 cell division cycle } 14 \text { homolog B } \\
\text { (S. cerevisiae) }\end{array}$ & 2.09 & 0.027588 & cell cycle control \\
\hline TGFBR1: Transforming growth factor, beta receptor I & 1.99 & 0.015786 & cell cycle arrest in epithelial cells; growth inhibition, cell apoptosis \\
\hline $\begin{array}{l}\text { PIK3C2A: Phosphoinositide-3-kinase, class 2, alpha } \\
\text { polypeptide }\end{array}$ & 1.63 & 0.037372 & $\begin{array}{l}\text { functions in insulin signaling, premature senescence and } \\
\text { oxidative apoptosis }\end{array}$ \\
\hline AKAP10: A kinase (PRKA) anchor protein 10 & 1.59 & 0.024294 & control of cell proliferation \\
\hline DLC1: deleted in liver cancer 1 & 1.58 & 0.041191 & metastasis suppressor gene, EMT arrest \\
\hline BRPF3: bromodomain and PHD finger containing, 3 & 1.44 & 0.035113 & $\begin{array}{l}\text { promotes formation of acetyltransferase complexes, stimulates } \\
\text { transcription }\end{array}$ \\
\hline $\begin{array}{l}\text { SLC20A1: Solute carrier family } 20 \text { (phosphate } \\
\text { transporter), member } 1\end{array}$ & 1.40 & 0.042665 & $\begin{array}{l}\text { cellular metabolism, signal transduction, and nucleic acid and } \\
\text { lipid synthesis }\end{array}$ \\
\hline RASEF: RAS and EF-hand domain containing & 1.39 & 0.045602 & $\begin{array}{l}\text { tumor suppressor, induction of apoptosis, inhibition of } \\
\text { proliferation }\end{array}$ \\
\hline MLL: myeloid/lymphoid or mixed-lineage leukemia & 1.38 & 0.024547 & $\begin{array}{l}\text { regulates neural progenitor proliferation and neuronal and glial } \\
\text { differentiation }\end{array}$ \\
\hline CDK6: cyclin-dependent kinase 6 & 1.37 & 0.047985 & $\begin{array}{l}\text { augments accumulation of p53, decreases tumor growth when } \\
\text { overexpression }\end{array}$ \\
\hline IGF1R: insulin-like growth factor 1 receptor & 1.34 & 0.045232 & $\begin{array}{l}\text { stimulates stem cell differentiation via AKT activation; premature } \\
\text { senescence }\end{array}$ \\
\hline POU2F1: POU class 2 homeobox 1 & 1.34 & 0.032549 & $\begin{array}{l}\text { anti-inflammation/immune response, cell apoptosis, regulation } \\
\text { of NF-kappaB }\end{array}$ \\
\hline $\begin{array}{l}\text { IL6ST: interleukin } 6 \text { signal transducer (gp130, oncostatin } \\
\text { M receptor) }\end{array}$ & 1.29 & 0.022673 & stimulates osteoblast differentiation, maintains bone formation \\
\hline ZNF395: zinc finger protein 395 & 1.29 & 0.030385 & suppresses cell migration and invasion \\
\hline ERN2: endoplasmic reticulum to nucleus signaling 2 & 1.28 & 0.037335 & activation of the unfolded protein response \\
\hline $\begin{array}{l}\text { LGR5: leucine-rich repeat-containing G protein-coupled } \\
\text { receptor } 5\end{array}$ & 1.27 & 0.030355 & universal epithelial stem cell marker \\
\hline $\begin{array}{l}\text { IRAK1BP1: interleukin-1 receptor-associated kinase } 1 \\
\text { binding protein } 1\end{array}$ & 1.27 & 0.024291 & $\begin{array}{l}\text { downregulation of inflammatory cytokines, anti-inflammation, } \\
\text { growth inhibition }\end{array}$ \\
\hline ARIH2: Ariadne homolog 2 (Drosophila) & 1.26 & 0.032696 & inhibits cell proliferation \\
\hline \multicolumn{4}{|l|}{ II. Downregulated genes } \\
\hline NOTCH3: Notch homolog 3 (Drosophila) & -1.25 & 0.037102 & $\begin{array}{l}\text { EMT, maintenance of NSC in an undifferentiated quiescent state, } \\
\text { angiogenesis }\end{array}$ \\
\hline ASXL1: additional sex combs like 1 (Drosophila) & -1.25 & 0.016868 & suppresses adipogenesis, transcriptional repression \\
\hline $\begin{array}{l}\text { SEMA6A: sema, transmembrane, and cytoplasmic } \\
\text { domains, } 6 \mathrm{~A}\end{array}$ & -1.25 & 0.041608 & $\begin{array}{l}\text { vascular development; tumor angiogenesis; neuronal } \\
\text { development }\end{array}$ \\
\hline QPRT: quinolinate phosphoribosyltransferase & -1.25 & 0.027582 & $\begin{array}{l}\text { resistance to oxidative stress; suppression of spontaneous } \\
\text { cell death }\end{array}$ \\
\hline $\begin{array}{l}\text { GPRC5B: G protein-coupled receptor, family C, group 5, } \\
\text { member B }\end{array}$ & -1.26 & 0.029052 & $\begin{array}{l}\text { insulin resistance; inflammatory signaling; promotes } \\
\text { ERK1/2 activation }\end{array}$ \\
\hline TRO: trophinin & -1.26 & 0.033855 & $\begin{array}{l}\text { promotes EMT, invasive and metastatic phenotype; tumor } \\
\text { formation }\end{array}$ \\
\hline MFI2: antigen p97 identified by mAb 133.2 and 96.5 & -1.26 & 0.034824 & cell proliferation and tumorigenesis \\
\hline
\end{tabular}


Table 2 Transcriptional modulation in GSC by BMP7 treatment ${ }^{\mathrm{a}}$ (Continued)

\begin{tabular}{|c|c|c|c|}
\hline METTL3: methyltransferase like 3 & -1.28 & 0.046969 & plays a role in the efficiency of mRNA splicing and processing \\
\hline MTMR11: myotubularin related protein 11 & -1.35 & 0.017165 & unknown; cisplatin resistance-associated protein \\
\hline COL16A1: collagen, type XVI, alpha 1 & -1.37 & 0.020495 & stimulates tumor proliferation and invasion \\
\hline $\begin{array}{l}\text { SCARA5: Scavenger receptor class A, member } 5 \\
\text { (putative) }\end{array}$ & -1.40 & 0.024406 & innate immune response; inflammatory response \\
\hline CLEC7A: C-type lectin domain family 7, member A & -1.40 & 0.009915 & $\begin{array}{l}\text { innate immune response; inflammatory response; migration and } \\
\text { proliferation }\end{array}$ \\
\hline
\end{tabular}

NSC neural stem cells; EMT epithelial-to-mesenchymal transition

aProbe set signals on the expression array that were $\geq 1.25$-fold different in BMP7 treated GSC cultures ( $n=2$, GSC-parental and GSC-500 $\mu$ M TMZ) when compared to untreated GSC cultures ( $n=2$, GSC-parental and GSC-500 $\mu \mathrm{M} \mathrm{TMZ)} \mathrm{were} \mathrm{selected}$

suppressor (RASAL2, DLC1), EMT/migration/invasion arrest (DLC1, ZNF395), tumor suppressor/cell cycle control (CDC14B, TGFBR1, AKAP10, RASEF, ARIH2), cell differentiation and transcription activation (ATXN1, ZNF638, BRPF3, MLL, IGF1R, IL6ST), insulin signaling/glucose uptake/premature senescence (PIK3C2A, IGF1R), and antiinflammation/immune response (POU2F1, IRAK1BP1). CD44, a receptor for hyaluronic acid, was determined to be a top 3 upregulated gene; it has been reported that CD44 modulated SMAD1 activation in the BMP7 signaling pathway in chondrocytes [30], and inhibits inflammatory bone loss [31]. Correspondingly, genes down-regulated by BMP7 treatment are mostly associated with EMT/migration/invasion (NOTCH3, TRO, COL16A1), stemness/ anti-differentiation/transcriptional repression (NOTCH3, ASXL1), DNA repair/anti-apoptosis/resistance to oxidative stress (QPRT), cell proliferation/tumorigenesis (MFI2, COL16A1), insulin resistance (GPRC5B), angiogenesis (NOTCH3, SEMA6A), and inflammation/immune response (GPRC5B, SCARA5, CLEC7A). The selected genes with distinct expression levels in cells were confirmed by sqRT-PCR analysis (data not shown). These gene profiles therefore, support the view that the molecular properties of EMT and stemness in GSC may be the two key factors triggering drug resistance. The data also suggest that BMP7 possesses the ability of anti-EMT/migration/invasion, induction of tumor stem cell differentiation/senescence, and down-regulation of MGMT and drug efflux transporters, thereby allowing for sensitization of GSC to low-dose TMZ treatment.

\section{BMP7 synergizes TMZ in treatment of GSC and extends animal survival}

To test whether anti-tumor synergy of combination treatment in culture can be translated to in vivo treatment, we performed a proof-of-principle experiment to compare the treatment efficacy of $0.01 \%$ DMSO (untreated), TMZ, BMP7, and combination of BMP7 and $\mathrm{TMZ}$, on preventing tumor initiation and progression (enrichment of resistant clones) in animals inoculated with GSC-parental. We chose D431-parental as the treatment model, because the mice that were injected with D431-parental had the shortest lifespan when compared to those injected with a different line. Moreover, D431-parental contains the highest \% of $\mathrm{CD}_{133^{+}}$cells ( $35 \%)$ among 3 GSC lines [20]. The administration routes, and dosing schedules are described in Material and Methods. Treatment with TMZ alone did not show a survival benefit (59-63 days) when compared to the untreated animal group (52-63 days) ( $p=0.9005)$ (Fig. 5c). Although BMP7 alone did not effectively stop GSC growth in culture, treatment with BMP7 alone demonstrated significantly extended survival of animals (70-79 days) when compared to untreated $(p=0.0025)$ or treated with TMZ alone ( $p=0.0017)$ (Fig. $5 c)$. The combination of BMP7 with TMZ further showed a smaller, but significant prolongation of survival (73-86 days) when compared to treatment with BMP7 alone $(p=0.0489)$ (Fig. 5c). Although all mice died of tumor development, a more pronounced vascularity was seen in untreated and TMZ-treated animals when compared to those treated with BMP7 and combination therapy (Fig. 5d, e). Moreover, there was less tumor spreading seen in animals treated with combination therapy (Fig. 5d, e). These results suggest that BMP7 treatment not only can attenuate the tumorigenicity of GSC and delay tumor progression, but also can further synergize with TMZ in enhancing the suppression of the tumor growth thereby providing a greater survival benefit to animals.

\section{Discussion}

In this study, we used molecular profiles of MGMTexpressing GSC that survived high-dose TMZ treatment, to probe defense signatures which could be potential treatment targets for sensitizing GSC to the clinically relevant dose of TMZ. Using this non-biased strategy, we have identified informative gene profiles that are likely to contribute to resistance to high-dose TMZ treatment. These protective stress response profiles are similar to our previous finding in GSC clones that survived radiochemotherapy (RT + TMZ) [13], which expressed molecular and functional characteristics resembling the anti-aging/anti-stress effects of caloric/ 
glucose restriction (GR), by which both insulin-like growth factor 1 (IGF1) and insulin/Akt signaling were reduced [32-34]. The transcription profiles suggested that the stress/drug resistance of GSC-500 $\mu \mathrm{M}$ TMZ is associated with cellular quiescence, EMT/invasiveness, suppressed growth and differentiation, and impaired insulin/Akt signaling. We unintentionally found BMP7 to be a top down-regulated gene in GSC-500 $\mu \mathrm{M}$ TMZ, and thus hypothesized that reduced BMP7 expression/ signaling helped them maintain their dedifferentiated state, which prevents them from premature senescence, and renders them more resistant to standard treatment, since it only targets more differentiated/aging cells [35]. Indeed, treatment with BMP7 alone allows for delaying tumor development/progression without TMZ compared to untreatment or treatment with TMZ alone, suggesting that the anti-tumor activity of BMP7 is independent of MGMT status in GSC. This notion is further supported by the finding that BMP7 treatment does not reverse the unmethylation status of GSC. Our data support the view that induction of cell senescence/aging and loss of EMT/migration/invasion properties by BMP7 treatment are likely to contribute to the reduction of tumorigenesis and progression, leading to prolonged animal survival. Moreover, BMP7 treatment downregulates the expression of MGMT and ATP-binding cassette drug efflux transporters in GSC may provide an additional support mechanism to synergize low-dose TMZ in treatment of GSC. Therefore, BMP7 treatment induces cooperative mechanisms which allow for sensitization of GSC to low-dose TMZ treatment, and extends animal survival. Similar to our finding, a recent study showed that MGMT methylation status does not predict TMZ response in GSC model, and both methylated and unmethylated MGMT bands can be amplified in TMZ-resistant GSC lines [36]. Another study found that some GBM lines resistant to TMZ treatment do not express MGMT protein, but rather exhibit a downregulation of DNA mismatch repair protein or reduced methylation of LINE-1 repetitive elements (enhances transposon activity) [37]. Therefore, we believe that down-regulation of MGMT expression by BMP7 is not the sole mechanism allowing for GSC responding to low-dose TMZ treatment.

BMP7 is a member of the transforming growth factor$\beta$ (TGF- $\beta$ ) superfamily of growth factors. The binding of BMP7 to its receptors, BMP type 1 and type 2 receptors (BMPR1/2), induces the phosphorylation of intracellular SMAD1/5/8, which can block the nuclear translocation of phosphorylated SMADs $2 / 3$ induced by TGF- $\beta$, which in turn results in suppressed TGF- $\beta$ signaling. BMP7 plays a pivotal role in the osteoblast differentiation/bone formation, kidney development, and promoting brown adipocyte differentiation [38-40]. Recently, BMP7 has been implicated in regulation of cancer pathogenesis and metastasis, possibly due to its ability to counteract TGF$\beta$-induced, SMAD3-dependent EMT [41, 42]. Reduced levels of BMP7 in primary breast and lung cancer tissues are significantly associated with the formation of clinically overt bone metastases for breast cancer patients and lymph node metastasis for lung cancer patients [43, 44]. Down-regulated BMP7 expression was also determined in primary human prostate cancer tissue when compared with normal prostate luminal epithelium [45]. The animal studies further demonstrated that BMP7 treatment significantly inhibited internal bone growth of breast cancer cells and prostate cancer bone metastases, suggesting that reduced BMP7 signaling in tumor cells may enhance tumorigenesis and EMT with the development of metastatic properties via enhanced capacity for cell migration and invasion [43, 45]. Our previous [13] and current data support the view that EMT linked with dedifferentiation/stemness are possibly underlying treatment resistance of GSC, which can be overridden by augmenting BMP7 signaling. The removal of factors associated with stemness or anti-stress properties in GSC by BMP7 treatment is evident by demonstrating the significantly downregulation of mRNA levels of CD133, MGMT, and efflux transporters with concomitant induction of cell senescence and susceptibility to low-dose TMZ treatment. A previous study has shown that induction of EMT in mammary epithelial cells by exposure to TGF- $\beta 1$ or overexpression of Snail or Twist (EMT-inducing transcription factors), can generate cells with stem cell properties [46]. Another study also found that ZEB1, an EMT activator, represses expression of stemnessinhibiting microRNA [47]. Likewise, we previously found that primary glioblastoma possess molecular properties of mesenchymal stem cells (MSC) and express cellular and molecular markers that have been implicated in EMT/myofibroblastic phenotype [48]. In particular, we found primary glioblastoma tumor cells express CD105 (endoglin), which is an MSC surface marker and a component of the TGF- $\beta$ receptor complex that binds to TGF- $\beta 1$ and TGF- $\beta 3$, and modulates TGF- $\beta$ signaling [48], thus suggesting a direct link between TGF- $\beta$ induced EMT and the gain of stem cell properties in glioblastoma and GSC. TGF- $\beta 1$ promotes hematopoietic stem cell quiescence by downregulating Akt activity and upregulating FOXO3 activity [49]. Likewise, we also found that GSC clones sensitive to radiochemotherapy (RT + TMZ) exhibited activated Akt activity with increased glucose usage, whereas resistant clones expressed upregulated CD133, SOX2 and MGMT, with reduced Akt activity and increased AMPK-SIRT1-FOXO Axis and favored the fatty-acid oxidation pathway for their energy source [13]. In this study, we also found that treatment with BMP7, an antagonist of TGF- $\beta$ 
system, downregulated EMT and stemness transcription program accompanied by upregulation of genes associated with insulin signaling/AKT and cell senescence, suggesting that BMP7 modulates stemness and EMT may be involved in a metabolic switch, which led to increased drug sensitivity. Similarly, a recent study showed that BMP2 can sensitize glioblastoma-stem-like cells to TMZ $(500 \mu \mathrm{M})$ by downregulating both hypoxiainducible factor- $1 \alpha$ (HIF-1 $\alpha)$ and MGMT [50]. The study also demonstrated a direct binding of HIFs to the MGMT promoter under hypoxia, and the treatment with BMP2 can abrogate HIF-1a binding to MGMT promoter [50]. The hypoxia/HIF-dependent promotion of the stemness/cellular quiescence and EMT in cancer progression has been well addressed and reviewed [51-53]. Correspondingly, it was reported that ABC efflux transporters contain several binding sites for EMTinducing transcription factors, and overexpression of Twist, Snail, and FOXC2 can increase promoter activity of $\mathrm{ABC}$ efflux transporters by binds directly to the E-box elements of $\mathrm{ABC}$ efflux transporters [54]. These findings therefore support the notion that BMP7-mediated downregulation of CD133, MGMT and efflux transporters accompanied with increase sensitivity to TMZ may be achieved via the removal of factors that promote EMT and stemness properties in GSC.

We previously reported that GSC clones surviving radiochemotherapy (RT + TMZ), or purified $\mathrm{CD}_{133^{+}}$GSC, expressed upregulated angiogenesis- and EMT-associated genes $[13,17]$. In this study, we further found that BMP7 treatment markedly upregulates genes associated with cell differentiation and senescence while downregulates genes associated with stemness properties in GSC, including CD133 expression, suggesting that the expression of CD133 may be an indication of both stemness and drug resistance in GSC [22-24]. Recent reports indicated that CD133 is a marker of bioenergetic stress in hypoxic human glioma [55] and that activation of hypoxia/HIF1alpha enhanced the self-renewal activity of CD133 ${ }^{+}$GSC and inhibited the induction of CSC differentiation [56]. Moreover, the expression of CD133 facilitates EMT [57], whereas CD133 silencing inhibits stemness properties and enhances chemoradiosensitivity of tumor stem cells [58]. In this study, we identified several reported EMT inducers as molecular signatures of GSC-500 $\mu \mathrm{M}$ TMZ, including MCAM, FN1, and MALAT1 [59-61]. Correspondingly, $\mathrm{NOTCH} 3$, which both gates neural stem cell activation [62] and contributes to TGF- $\beta$-induced EMT [63], was detected as a downregulated gene by BMP7 treatment. Meanwhile, a NOTCH signaling repressor, ATXN1 [64], was identified as an upregulated gene by BMP7 treatment. Thus, maintaining the low activity of BMP7 signaling in GSC may be required for sustaining EMT, stemness, and multidrug-resistant phenotype. Our finding is in agreement with that of others showing that BMP7 release from endogenous neural precursor cells can induce tumor stem cell differentiation and reduce the ability for tumor initiation, therefore, providing a protective action in animals [65]. Likewise, treatment with a BMP7 variant suppressed the tumorigenicity of stem-like glioblastoma cells and reduced angiogenesis and brain invasion [66]. The optical imaging study further provided direct evidence of BMP7-induced cell cycle arrest in glioma model [67]. Notably, it was reported that BMP7-induced senescence of prostate cancer stem-like cells is reversible; withdrawal of BMP7 treatment restarted growth of these cells in bone [68]. Therefore, combination with chemotherapy would provide extended survival time by eliminating the cells, preventing them from regrowing back. Genetic approaches for elucidation of mechanisms by which BMP7 downregulates MGMT, ABC efflux transporters, stemness, and EMT would further facilitate our understanding the process and ability to identify new treatment targets and strategies for preventing treatment resistance and tumor recurrence.

\section{Conclusion}

The data presented in this study showed that BMP7 treatment can sensitize MGMT-expressing GSC to the clinically relevant dose of TMZ both in vitro and in vivo. The gene profiles pointed out that BMP7-mediated TMZ sensitization in GSC may be associated with reprogramming of transcriptional profiles, particularly the downregulation of genes which contributed to EMT/migration/invasion, stemness, and drug resistance. Our data therefore, suggest a potential therapeutic utility of BMP7, a neuroprotective agent in cerebral hypoxia/ischemia $[69,70]$, combined with TMZ, for treating newly diagnosed glioblastoma or recurrent diseases exhibiting unmethylated MGMT.

\section{Methods}

\section{Cell cultures}

Glioblastoma stem cell (GSC) cultures used in this study were established from glioblastoma tumor tissues derived from patients who underwent surgery at Ronald Reagan UCLA Medical Center. All samples collected were under patients' written consent, and were approved by the UCLA Institutional Review Board. The tumors were enzyme-digested and washed, followed by red blood cell (RBC) lysis of the pellet. The primary cells were cultured in a serum-free stem cell culture medium consisting of DMEM/Ham's F-12 (Mediatech, Manassas, VA), $20 \mathrm{ng} / \mathrm{ml}$ human recombinant epidermal growth factor (EGF, Sigma-Aldrich, St. Louis, MO), $20 \mathrm{ng} / \mathrm{ml}$ basic fibroblast growth factor (FGF, Chemicon, Billerica, MA), $10 \mathrm{ng} / \mathrm{ml}$ leukemia inhibitory factor (LIF, Chemicon), and B27 without vitamin A (Invitrogen, Carlsbad, 
CA). The tumor spheres were dissociated and replated at clonal density and continually passaged until the clonogenic cells were stably maintained. As previously described [13, 17], the D431 GSC culture line was classified as mesenchymal subtype whereas S496 and E445 culture lines were classified as proneural (PN) subtype. All three tumorigenic GSC cultures contained $\mathrm{CD}_{133^{+}}$cells (39.5\%, $9.6 \%$ and $1.5 \%$ respectively), exhibited wild-type IDH1/IDH2 and unmethylated MGMT promoter and expressed MGMT transcripts (10, 14, Additional file 1: Figure S3).

\section{Isolation of clonogenic GSC resistant to high-dose TMZ}

GSC cultures were seeded at clonal density overnight, and treated with $500 \mu \mathrm{M}$ TMZ the next day. Fresh media was replaced every three days. TMZ treatment was repeated on day 7 after the first treatment to ensure that clonogenic survivors are truly resistant to $500 \mu \mathrm{M}$ TMZ. Clonogenic cells that have survived were isolated, expanded, and designated as GSC-500TMZ-C1 (treatment cycle 1). Established GSC-500TMZ-C1 cultures were then reseeded and re-treated with $500 \mu \mathrm{M}$ TMZ twice (day 1 and day 7), and the stable clonogenic cells continued to grow were harvested and designated as GSC-500TMZ-C2. In order to maintain resistant clones in the long-term cultures, cells were re-exposed to $500 \mu \mathrm{M} \mathrm{TMZ}$ treatment after thawing or prior to using in experiments.

\section{Cell proliferation}

The effects of TMZ or siRNA treatment on GSC growth were determined by a 3-(4, 5-dimethylthiazol-2-yl)-5-(3carboxymethoxyphenyl)-2-(4-sulfophenyl)-2H-tetrazolium (MTS/PMS) colorimetric assay according to the manufacturer's instructions (Promega).

Cells were seeded in 96-well tissue culture plates at a density of 6,000-10,000 cells per well per $100 \mu \mathrm{L}$ stem cell media in triplicate in the presence or absence of indicated treatment. Cells were incubated for $48-72 \mathrm{~h}$, and absorbance was measured at $490 \mathrm{~nm}$ after a 4-hour incubation with MTS/PMS reagents.

\section{Cell apoptosis}

Cell apoptosis in BMP7- and TMZ-treated GSC was determined by Apo-ONE ${ }^{\oplus}$ Homogeneous Caspase-3/7 Assay kit (Promega), according to the manufacturer's protocol. One hundred microliters Homogeneous Caspase-3/7 Reagent was added to each well followed by 2 min mixing on a plate shaker. Plates were incubated at room temperature for $2 \mathrm{~h}$. Fluorescence intensity was measured with a fluorescence microplate reader (Synergy HT, BioTek) at the excitation and emission wavelengths of $485 \mathrm{~nm}$ and $528 \mathrm{~nm}$ respectively. Multiple readings were taken at one-hr intervals. Data are expressed as the relative fluorescence units (RFU).

\section{Cell-cycle distribution}

$2-5 \times 10^{5}$ dissociated cells were washed twice with cold PBS. Cell pellets were resuspended in $1 \mathrm{ml}$ propidium iodide hypotonic DNA staining buffer $(50 \mathrm{mg} / \mathrm{ml}$ propidium iodide, $0.1 \%$ Triton $\mathrm{X}-100$, and $0.1 \%$ sodium citrate in PBS) and mix well. Samples were kept in $4{ }^{\circ} \mathrm{C}$ away from light for a maximum of $1 \mathrm{~h}$ before acquisition on the flow cytometer for cell cycle analysis (FACScan, Becton Dickinson), which used DNA content as a measure of progression in cell cycle and as means of detecting apoptotic cells. Apoptotic cells with degraded DNA were detected as a hypodiploid or "sub-G1" peak in a DNA histogram.

\section{Microarray procedures, data analysis and gene annotation}

Molecular profiling and analysis were performed as described [17]. Briefly, cDNA was generated and converted to cRNA probes using standard Affymetrix protocols and hybridized to Affymetrix GeneChip U133 Plus 2.0 Array. The chips were scanned using the GeneArray scanner (Affymetrix). The CEL files generated by the Affymetrix Microarray Suite version 5.0 were converted into DCP files using the DNA-Chip Analyzer (dChip/2008; http:// www.hsph.harvard.edu/cli/complab/dchip/). The DCP files were globally normalized, and gene expression values were generated using the dChip implementation of perfectmatch minus mismatch model-based expression index. All group comparisons were performed in dChip. Functional annotation of individual genes was obtained from NCBI/ Entrez Gene (http://www.ncbi.nlm.nih.gov/sites/entrez), the published literature in PubMed Central (NCBI/PubMed), GeneCards (http://www.genecards.org/), and Protein knowledge base (UniProtKB) (http://beta.uniprot.org/). All microarray CEL files analyzed in this study are accessible from the Gene Expression Omnibus (GEO) (Series Accession number: GSE68071).

\section{Semi-quantitative reverse transcriptase polymerase chain reaction (sqRT-PCR) analysis}

Cells were subjected to total RNA extraction using RNeasy kit (Qiagen, Valencia, CA). Two micrograms of total RNA from each sample were reverse transcribed to cDNA using a TaqMan RT Reagent Kit (Applied Biosystems). Thirty cycles of PCR amplification was performed on an Eppendorf gradient thermocycler, using $5 \mu \mathrm{L}$ cDNA, SYBR Green PCR Core Reagents (Applied Biosystems) and gene-specific primers (Invitrogen). The signal intensity of each specific gene was quantified using Image Lab ${ }^{\text {Th }}$ Software (Gel Doc ${ }^{\text {th }}$ EZ System, Bio-Rad). The band intensity of each sample was normalized to the corresponding $\beta$-actin band intensity in order to obtain the relative level of gene expression. The primer sequences and expected sizes of amplified PCR products are described in Additional file 1: Table S1. 


\section{Western blot analysis}

$30 \mu \mathrm{g}$ protein from each sample were separated on 4-20\% gradient SDS-PAGE (Bio-Rad) and transferred onto a PVDF membrane. The blots were incubated with phospho-Smad1 (Ser463/465)/ Smad5 (Ser463/465)/ Smad9 (Smad8) (Ser465/467) antibody (Cell Signaling) for overnight at $4{ }^{\circ} \mathrm{C}$. Anti- $\beta$-actin (Cell Signaling) was used as internal control. The blots were washed and incubated with horseradish peroxidase-conjugated anti-rabbit IgG for $1 \mathrm{~h}$. After washing, blots were incubated with Pierce Supersignal ECL substrate, and exposed to X-ray films.

\section{siRNA transfection}

A reverse transfection protocol was done to deliver nonsilencing negative control siRNA (scrambled siRNA) (Ambion), glyceraldehyde-3-phosphate dehydrogenase (GAPDH) or gene-specific siRNA (Ambion), into GSCs as previously described [13]. The transfection efficiency and cellular toxicity due to transfection were monitored using KDalert ${ }^{\mathrm{TM}}$ GAPDH Assay Kit (Invitrogen). Briefly, a transfection complex was prepared by diluting siRNA in $10 \mu \mathrm{l}$ OPTI-MEMI (Invitrogen) then mixing with $10 \mu \mathrm{L}$ OPTI-MEMI containing $0.3 \mathrm{uL}$ Lipofectamine RNAiMAX transfection reagent (Invitrogen). The siRNA transfectant was then added into each well in a 96-well plate followed by seeding 6000-9000 cells in $100 \mu \mathrm{L}$ media to give a final siRNA concentration of $30 \mathrm{nM}$ in each well. Targeted gene silencing was determined $72 \mathrm{~h}$ after transfection by sqRT-PCR, using a Power SYBRH Green Cells-to-CTTM Kit (Ambion).

\section{Methylation-specific PCR (MSP) analysis}

Genomic DNA was subjected to bisulfite treatment using the EZ DNA Methylation-Gold ${ }^{\mathrm{Tu}}$ Kit (Zymo Research) following the manufacturer's instructions. The promoter MGMT-MSP was performed using a two-step nested approach to amplify both methylated and unmethylated MGMT separately as described previously [71]. Total human genomic DNA methylated by bacterial DNA methyltransferase and whole genome amplified DNA were used as positive and negative controls for methylated alleles of MGMT, respectively. The PCR products were resolved on $4 \%$ low melting point agarose gels.

\section{Intracranial tumor formation, BMP7 treatment, and histopathologic analysis}

To test the tumorigenic capacity of GSC, $10^{5}$ viable cells in a volume of $3 \mu \mathrm{l}$ culture media were engrafted intracranially into anesthetized NOD (CB17-Prkdcscid/J) mice (5 weeks old; $15-16 \mathrm{~g}$ ). Mice were then maintained until neurological signs were observed, at which point they were sacrificed. The brains were removed, fixed in $4 \%$ formalin, paraffin-embedded, and sectioned. Histopathologic analyses were done on paraffin slides stained with hematoxylin-eosin (H-E) staining per standard technique. To test whether BMP7 can sensitize TMZ for treatment of GSC in vivo, mice were randomly divided into four groups (5 mice per group) and each group was received the following treatments: group 1, $0.01 \%$ DMSO; group 2, TMZ; group3, BMP7; group 4, BMP7 + TMZ. GSC cells $\left(10^{5} / 3 \mu \mathrm{l} /\right.$ animal $)$ were intracranially injected followed by local delivery of vehicle $(0.01 \%$ DMSO in $\left.100 \mu \mathrm{H}_{2} \mathrm{O}\right)$ or TMZ $(100 \mu \mathrm{l}$ of $35 \mu \mathrm{M}$ TMZ) for group 1 and group 2 mice or BMP7 (10 ng in $100 \mu \mathrm{l}$ water) for group 3 and group 4 mice using an osmotic minipump (Alzet, USA, model 1007D). The sterile pump was implanted subcutaneously (s.c.) onto the back of animals, and the drug solutions were delivered through the cannula, which was placed through a small skull burr hole onto the pial surface where tumor cells were implanted. On day 7 after local treatment, the mice of group 2 were continuously treated with TMZ (66 mg/ $\mathrm{kg}$ ) via oral gavage daily for 5 days, the mice of group 3 received intraperitoneal injection of BMP7 ( $2 \mu \mathrm{g} /$ day) for 5 days and mice group 4 received both BMP7 (morning) and TMZ (afternoon) for 5 days. Animals were maintained until neurological signs were observed. Immediately after sacrifice, the brains were removed and subjected to histopathological analysis. All animal experiments in this study were under a protocol approved by the UCLA Institutional Animal Research Committee.

\section{Statistical analysis}

Each experiment was set up in triplicate and repeated at least twice. Data were expressed as means \pm SD and analyzed using 1-way ANOVA tests, depending on homogeneity of variances. Cumulative survival probabilities were calculated using the Kaplan-Meier method. The log-rank test was used to compare survival across groups. All p-values were 2-sided, and those lower than 0.05 were considered significant. SPSS v19.0 for Windows software was used for all statistical analysis.

\section{Additional file}

Additional file 1: Supplementary Materials. (DOCX 1426 kb)

Competing interests

The authors have declared that no competing interests exist.

\section{Authors' contributions}

$J L T, S Y, K Y, W M, C L T$ conceived and designed the experiments. JLT, SY, JCM, $K Y, Y Z$ conducted and managed animal experiments. JLT, JCM, $I H, Y B, A S$ carried out the cellular and molecular studies. KY and WHY performed pathology analysis. LML, SFN, TFC, WHY, AL contributed patient tumor samples and provided tumor information, analysis tools, and MGMT methylation status. JLT and CLT wrote the manuscript and performed statistical analysis. All authors read and approved the final manuscript. 


\section{Acknowledgement}

We thank UCLA Brain Tumor Translational Resource, Jonsson Comprehensive Cancer Center (NIH P30 CA-16042), and Center for AIDS Research Flow Cytometry Core Facility (NIH 5P30 Al-28697) for their technical assistance. We also acknowledge many outstanding references providing information about gene functions in Tables 1 and 2 that are not cited here. This work was supported by grants from the American Cancer Society (RSG-07-109-01-CCE) (CLT), National Cancer Institute (1 R21 CA140912-01) (CLT), National Institute of Health (1DP2OD006444-01) (CLT), and the Bradley Zankel Foundation $(C L T)$. The funders had no role in study design, data collection and analysis, decision to publish, or preparation of the manuscript.

\section{Author details}

'Department of Surgery/Surgical Oncology, David Geffen School of Medicine, University of California at Los Angeles, Los Angeles, CA, USA. ${ }^{2}$ Department of Neurosurgery, Guangzhou General Hospital of Guangzhou Military Command, Guangzhou, Guangdong, China. ${ }^{3}$ Department of Advanced Molecular and Cell Therapy, Kyushu University Hospital, Higashiku, Fukuoka, Japan. ${ }^{4}$ Department of Orthopedics, Zhongshan Hospital, Xiamen University, Xiamen, China. ${ }^{5}$ Department of Radiation-Oncology, David Geffen School of Medicine, University of California Los Angeles, Los Angeles, CA, USA. ${ }^{6}$ Department of Neurosurgery, David Geffen School of Medicine, University of California at Los Angeles, Los Angeles, CA, USA. ${ }^{7}$ Department of Human Genetics, David Geffen School of Medicine, University of California at Los Angeles, Los Angeles, CA, USA. ${ }^{8}$ Department of Neurology, David Geffen School of Medicine, University of California at Los Angeles, Los Angeles, CA, USA. ${ }^{9}$ Department of Pathology and Laboratory Medicine, David Geffen School of Medicine, University of California at Los Angeles, Los Angeles, CA, USA. ${ }^{10}$ Jonsson Comprehensive Cancer Center, University of California at Los Angeles, Los Angeles, USA.

Received: 28 April 2015 Accepted: 20 October 2015

Published online: 06 November 2015

\section{References}

1. Stupp R, Hegi ME, Mason WP, van den Bent MJ, Taphoorn MJ, Janzer RC, et al. Effects of radiotherapy with concomitant and adjuvant temozolomide versus radiotherapy alone on survival in glioblastoma in a randomised phase III study: 5-year analysis of the EORTC-NCIC trial. Lancet Oncol. 2009;10:459-66.

2. Hegi ME, Diserens AC, Gorlia T, Hamou MF, de Tribolet N, Weller M, et al. MGMT gene silencing and benefit from temozolomide in glioblastoma. N Engl J Med. 2005;352:997-03.

3. Jacinto FV, Esteller M. MGMT hypermethylation: a prognostic foe, a predictive friend. DNA Repair. 2007:6:1155-60.

4. Roos WP, Batista LF, Naumann SC, Wick W, Weller M, Menck CF, et al. Apoptosis in malignant glioma cells triggered by the temozolomideinduced DNA lesion O6-methylguanine. Oncogene. 2007;26:186-97.

5. Fu D, Calvo JA, Samson LD. Balancing repair and tolerance of DNA damage caused by alkylating agents. Nat Rev Cancer. 2012;12:104-20.

6. Pegg AE, Dolan ME, Moschel RC. Structure, function, and inhibition of O6-alkylguanine-DNA alkyltransferase. Prog Nucleic Acid Res Mol Biol. 1995:51:167-223.

7. Nguyen $S A$, Stechishin OD, Luchman HA, Lun XQ, Senger DL, Robbins SM, et al. Novel MSH6 mutations in treatment-naïve glioblastoma and anaplastic oligodendroglioma contribute to temozolomide resistance independently of MGMT promoter methylation. Clin Cancer Res. 2014;20:4894-903.

8. Hegi ME, Diserens AC, Godard S, Dietrich PY, Regli L, Ostermann S, et al. Clinical trial substantiates the predictive value of 0-6-methylguanine-DNA methyltransferase promoter methylation in glioblastoma patients treated with temozolomide. Clin Cancer Res. 2004;10:1871-74.

9. Lalezari S, Chou AP, Tran A, Solis OE, Khanlou N, Chen W, et al. Combined analysis of O6-methylguanine-DNA methyltransferase protein expression and promoter methylation provides optimized prognostication of glioblastoma outcome. Neuro Oncol. 2013;15:370-81.

10. Beier D, Schulz JB, Beier CP. Chemoresistance of glioblastoma cancer stem cells-much more complex than expected. Mol Cancer. 2011;10:128. Review.

11. Eramo A, Ricci-Vitiani L, Zeuner A, Pallini R, Lotti F, Sette G, et al. Chemotherapy resistance of glioblastoma stem cells. Cell Death Differ. 2006;13:1238-41.
12. Bao S, Wu Q, McLendon RE, Hao Y, Shi Q, Hjelmeland AB, et al. Glioma stem cells promote radioresistance by preferential activation of the DNA damage response. Nature. 2006;444:756-60.

13. Ye F, Zhang Y, Liu Y, Yamada K, Tso JL, Menjivar JC, et al. Protective properties of radio-chemoresistant glioblastoma stem cell clones are associated with metabolic adaptation to reduced glucose dependence. PLoS One. 2013;8:e80397.

14. Chen J, Li Y, Yu TS, McKay RM, Burns DK, Kernie SG, et al. A restricted cell population propagates glioblastoma growth after chemotherapy. Nature. 2012;488:522-6.

15. Galli R, Binda E, Orfanelli U, Cipelletti B, Gritti A, De Vitis S, et al. Isolation and characterization of tumorigenic, stem-like neural precursors from human glioblastoma. Cancer Res. 2004;64:7011-21.

16. Singh SK, Hawkins C, Clarke ID, Squire JA, Bayani J, Hide T, et al. Identification of human brain tumour initiating cells. Nature. 2004;432:396-401.

17. Liu Q, Nguyen DH, Dong Q, Shitaku P, Chung K, Liu OY, et al. Molecular properties of CD133+ glioblastoma stem cells derived from treatmentrefractory recurrent brain tumors. J Neurooncol. 2009;94:1-19.

18. Beier D, Röhrl S, Pillai DR, Schwarz S, Kunz-Schughart LA, Leukel P, et al. Temozolomide preferentially depletes cancer stem cells in glioblastoma. Cancer Res. 2008:68:5706-15.

19. Rosso L, Brock CS, Gallo JM, Saleem A, Price PM, Turkheimer FE, et al. A new model for prediction of drug distribution in tumor and normal tissues: pharmacokinetics of temozolomide in glioma patients. Cancer Res. 2009;69:120-7.

20. Liu Y, Ye F, Yamada K, Tso JL, Zhang Y, Nguyen DH, et al. Autocrine endothelin-3/endothelin receptor B signaling maintains cellular and molecular properties of glioblastoma stem cells. Mol Cancer Res. 2011;9:1668-85.

21. Chang CF, Lin SZ, Chiang YH, Morales M, Chou J, Lein P, et al. Intravenous administration of bone morphogenetic protein-7 after ischemia improves motor function in stroke rats. Stroke. 2003;34:558-64.

22. Ulasov IV, Nandi S, Dey M, Sonabend AM, Lesniak MS. Inhibition of Sonic hedgehog and Notch pathways enhances sensitivity of CD133(+) glioma stem cells to temozolomide therapy. Mol Med. 2011;17:103-12.

23. Liu G, Yuan X, Zeng Z, Tunici P, Ng H, Abdulkadir IR, et al. Analysis of gene expression and chemoresistance of CD133+ cancer stem cells in glioblastoma. Mol Cancer. 2006:5:67.

24. Murat A, Migliavacca E, Gorlia T, Lambiv WL, Shay T, Hamou MF, et al. Stem cell-related self-renewal" signature and high epidermal growth factor receptor expression associated with resistance to concomitant chemoradiotherapy in glioblastoma. J Clin Oncol. 2008;26:3015-24

25. Schaich M, Kestel L, Pfirrmann M, Robel K, Illmer T, Kramer M, et al. A MDR1 (ABCB1) gene single nucleotide polymorphism predicts outcome of temozolomide treatment in glioblastoma patients. Ann Oncol. 2009;20:175-81.

26. Lin F, de Gooijer MC, Roig EM, Buil LC, Christner SM, Beumer JH, et al. $A B C B 1, A B C G 2$, and PTEN determine the response of glioblastoma to temozolomide and ABT-888 therapy. Clin Cancer Res. 2014;20:2703-13.

27. Bleau AM, Hambardzumyan D, Ozawa T, Fomchenko El, Huse JT, Brennan CW, et al. PTEN/PI3K/Akt pathway regulates the side population phenotype and ABCG2 activity in glioma tumor stem-like cells. Cell Stem Cell. 2009;4:226-35

28. Coskun V, Wu H, Blanchi B, Tsao S, Kim K, Zhao J, et al. CD133+ neural stem cells in the ependyma of mammalian postnatal forebrain. Proc Natl Acad Sci U S A. 2008;105:1026-31.

29. Imura T, Kornblum HI, Sofroniew MV. The predominant neural stem cell isolated from postnatal and adult forebrain but not early embryonic forebrain expresses GFAP. J Neurosci. 2003;23:2824-32.

30. Peterson RS, Andhare RA, Rousche KT, Knudson W, Wang W, Grossfield JB, et al. CD44 modulates Smad1 activation in the BMP-7 signaling pathway. J Cell Biol. 2004;166:1081-91.

31. Hayer S, Steiner G, Görtz B, Reiter E, Tohidast-Akrad M, Amling M, et al. CD44 is a determinant of inflammatory bone loss. J Exp Med. 2005;201:903-14.

32. Schulz TJ, Zarse K, Voigt A, Urban N, Birringer M, Ristow M. Glucose restriction extends Caenorhabditis elegans life span by inducing mitochondrial respiration and increasing oxidative stress. Cell Metab. 2007;6:280-93.

33. Blüher M, Kahn BB, Kahn CR. Extended longevity in mice lacking the insulin receptor in adipose tissue. Science. 2003;299:572-74. 
34. Fontana L, Partridge L, Longo VD. Extending healthy life span-from yeast to humans. Science. 2010;328:321-26.

35. Pistollato F, Abbadi S, Rampazzo E, Persano L, Della Puppa A, Frasson C, et al. Intratumoral hypoxic gradient drives stem cells distribution and MGMT expression in glioblastoma. Stem Cells. 2010;28:851-62.

36. Blough MD, Westgate MR, Beauchamp D, Kelly JJ, Stechishin O, Ramirez AL, et al. Sensitivity to temozolomide in brain tumor initiating cells. Neuro Oncol. 2010;12:756-60

37. Happold C, Roth P, Wick W, Schmidt N, Florea AM, Silginer M, et al. Distinct molecular mechanisms of acquired resistance to temozolomide in glioblastoma cells. J Neurochem. 2012;122:444-55.

38. Ozkaynak E, Rueger DC, Drier EA, Corbett C, Ridge RJ, Sampath TK, et al. OP-1 cDNA encodes an osteogenic protein in the TGF-beta family. EMBO J. 1990;9:2085-93.

39. Dudley AT, Lyons KM, Robertson EJ. A requirement for bone morphogenetic protein-7 during development of the mammalian kidney and eye. Genes Dev. 1995;9:2795-07.

40. Tseng YH, Kokkotou E, Schulz TJ, Huang TL, Winnay JN, Taniguchi CM, et al. New role of bone morphogenetic protein 7 in brown adipogenesis and energy expenditure. Nature. 2008;454:1000-4.

41. Zeisberg M, Hanai J, Sugimoto H, Mammoto T, Charytan D, Strutz F, et al. BMP-7 counteracts TGF-beta1-induced epithelial-to-mesenchymal transition and reverses chronic renal injury. Nat Med. 2003:9:964-8.

42. Zeisberg M, Shah AA, Kalluri R. Bone morphogenic protein-7 induces mesenchymal to epithelial transition in adult renal fibroblasts and facilitates regeneration of injured kidney. J Biol Chem. 2005;280:8094-100.

43. Buijs JT, Henriquez NV, van Overveld PG, van der Horst G, Que I, Schwaninger $\mathrm{R}$, et al. Bone morphogenetic protein 7 in the development and treatment of bone metastases from breast cancer. Cancer Res. 2007;67:8742-51.

44. Chen J, Ye L, Xie F, Yang Y, Zhang L, Jiang WG. Expression of bone morphogenetic protein 7 in lung cancer and its biological impact on lung cancer cells. Anticancer Res. 2010;30:1113-20.

45. Buijs JT, Rentsch CA, van der Horst G, van Overveld PG, Wetterwald A, Schwaninger $\mathrm{R}$, et al. BMP7, a putative regulator of epithelial homeostasis in the human prostate, is a potent inhibitor of prostate cancer bone metastasis in vivo. Am J Pathol. 2007:171:1047-57.

46. Mani SA, Guo W, Liao MJ, Eaton EN, Ayyanan A, Zhou AY, et al. The epithelial-mesenchymal transition generates cells with properties of stem cells. Cell. 2008;133:704-15.

47. Wellner U, Schubert J, Burk UC, Schmalhofer O, Zhu F, Sonntag A, et al. The EMT-activator ZEB1 promotes tumorigenicity by repressing stemnessinhibiting microRNAs. Nat Cell Biol. 2009;11:1487-95.

48. Tso CL, Shintaku P, Chen J, Liu Q, Liu J, Chen Z, et al. Primary glioblastomas express mesenchymal stem-like properties. Mol Cancer Res. 2006:4:607-19.

49. Yamazaki S, Iwama A, Takayanagi S, Eto K, Ema H, Nakauchi H. TGF-beta as a candidate bone marrow niche signal to induce hematopoietic stem cell hibernation. Blood. 2009;113:1250-56.

50. Persano L, Pistollato F, Rampazzo E, Della Puppa A, Abbadi S, Frasson C, et al. BMP2 sensitizes glioblastoma stem-like cells to Temozolomide by affecting HIF-1a stability and MGMT expression. Cell Death Dis. 2012;3:e412.

51. Huang SG, Zhang LL, Niu Q, Xiang GM, Liu LL, Jiang DN, et al. Hypoxia promotes epithelial-mesenchymal transition of hepatocellular carcinoma cells via inducing GLIPR-2 expression. PLoS One. 2013:8:e77497.

52. Philip B, Ito K, Moreno-Sánchez R, Ralph SJ. HIF expression and the role of hypoxic microenvironments within primary tumours as protective sites driving cancer stem cell renewal and metastatic progression. Carcinogenesis. 2013;34:1699-707.

53. Mimeault M, Batra SK. Hypoxia-inducing factors as master regulators of stemness properties and altered metabolism of cancer- and metastasisinitiating cells. J Cell Mol Med. 2013;17:30-54.

54. Saxena M, Stephens MA, Pathak H, Rangarajan A. Transcription factors that mediate epithelial-mesenchymal transition lead to multidrug resistance by upregulating ABC transporters. Cell Death Dis. 2011;2:e179.

55. Griquer CE, Oliva CR, Gobin E, Marcorelles P, Benos DJ, Lancaster Jr JR, et al. CD133 is a marker of bioenergetic stress in human glioma. PLoS One. 2008;3:e3655.

56. Soeda A, Park M, Lee D, Mintz A, Androutsellis-Theotokis A, McKay RD, et al. Hypoxia promotes expansion of the CD133-positive glioma stem cells through activation of HIF-1alpha. Oncogene. 2009;28:3949-59.

57. Ding Q, Miyazaki Y, Tsukasa K, Matsubara S, Yoshimitsu M, Takao S. CD133 facilitates epithelial-mesenchymal transition through interaction with the ERK pathway in pancreatic cancer metastasis. Mol Cancer. 2014;13:15.
58. Lan X, Wu YZ, Wang Y, Wu FR, Zang CB, Tang C, et al. CD133 silencing inhibits stemness properties and enhances chemoradiosensitivity in CD133positive liver cancer stem cells. Int J Mol Med. 2013;31:315-24.

59. Zeng Q, Li W, Lu D, Wu Z, Duan H, Luo Y, et al. CD146, an epithelialmesenchymal transition inducer, is associated with triple-negative breast cancer. Proc Natl Acad Sci U S A. 2012;109:1127-32.

60. Park J, Schwarzbauer JE. Mammary epithelial cell interactions with fibronectin stimulate epithelial-mesenchymal transition. Oncogene. 2014;33:1649-57

61. Fan $Y$, Shen B, Tan M, Mu X, Qin Y, Zhang F, et al. TGF-B-induced upregulation of malat1 promotes bladder cancer metastasis by associating with suz12. Clin Cancer Res. 2014;20:1531-41.

62. Alunni A, Krecsmarik M, Bosco A, Galant S, Pan L, Moens CB, et al. Notch3 signaling gates cell cycle entry and limits neural stem cell amplification in the adult pallium. Development. 2013;140:3335-47.

63. Liu L, Chen X, Wang Y, Qu Z, Lu Q, Zhao J, et al. Notch3 is important for TGF- $\beta$-induced epithelial-mesenchymal transition in non-small cell lung cancer bone metastasis by regulating ZEB-1. Cancer Gene Ther. 2014;21:364-72.

64. Tong X, Gui H, Jin F, Heck BW, Lin P, Ma J, et al. Ataxin-1 and Brother of ataxin-1 are components of the Notch signalling pathway. EMBO Rep. 2011;12:428-35

65. Chirasani SR, Sternjak A, Wend P, Momma S, Campos B, Herrmann IM, et al Bone morphogenetic protein-7 release from endogenous neural precursor cells suppresses the tumourigenicity of stem-like glioblastoma cells. Brain. 2010;133(Pt 7):1961-72.

66. Tate CM, Pallini R, Ricci-Vitiani L, Dowless M, Shiyanova T, D'Alessandris GQ, et al. A BMP7 variant inhibits the tumorigenic potential of glioblastoma stem-like cells. Cell Death Differ. 2012;19:1644-54.

67. Klose A, Waerzeggers Y, Monfared P, Vukicevic S, Kaijzel EL, Winkeler A, et al. Imaging bone morphogenetic protein 7 induced cell cycle arrest in experimental gliomas. Neoplasia. 2011;13:276-85.

68. Kobayashi A, Okuda H, Xing F, Pandey PR, Watabe M, Hirota S, et al. Bone morphogenetic protein 7 in dormancy and metastasis of prostate cancer stem-like cells in bone. J Exp Med. 2011;208:2641-55.

69. Bani-Yaghoub M, Tremblay RG, Ajji A, Nzau M, Gangaraju S, Chitty D, et al. Neuroregenerative strategies in the brain: emerging significance of bone morphogenetic protein 7 (BMP7). Biochem Cell Biol. 2008;86:361-9. Review.

70. Guan J, Li H, Lv T, Chen D, Yuan Y, Qu S. Bone morphogenetic protein-7 (BMP-7) mediates ischemic preconditioning-induced ischemic tolerance via attenuating apoptosis in rat brain. Biochem Biophys Res Commun. 2013:441:560-6.

71. Palmisano WA, Divine KK, Saccomanno G, Gilliland FD, Baylin SB, Herman JG, et al. Predicting lung cancer by detecting aberrant promoter methylation in sputum. Cancer Res. 2000;60:5954-58.

\section{Submit your next manuscript to BioMed Central and take full advantage of:}

- Convenient online submission

- Thorough peer review

- No space constraints or color figure charges

- Immediate publication on acceptance

- Inclusion in PubMed, CAS, Scopus and Google Scholar

- Research which is freely available for redistribution 